\title{
Evaluation of right ventricular function after cardiac surgery: The importance of tricuspid annular plane systolic excursion and right ventricular ejection fraction
}

\author{
Renata Garcia Gigorro, MD, PhD, ${ }^{a}$ Emilio Renes Carreño, MD, ${ }^{\mathrm{a}}$ Sandra Mayordomo, MD, ${ }^{\mathrm{b}}$ \\ Helena Marín, MD, ${ }^{\mathrm{c}}$ Jose Luis Perez Vela, MD, ${ }^{\mathrm{a}}$ María Angélica Corres Peiretti, MD, ${ }^{\mathrm{a}}$ and \\ Juan Carlos Montejo González, MD, $\mathrm{PhD}^{\mathrm{c}}$
}

\begin{abstract}
Objective: The evaluation of right ventricular systolic function is essential to the hemodynamic management of critically ill cardiac patients. Nevertheless, assessment of right ventricular function remains problematic. We sought to analyze the correlation between tricuspid annular plane systolic excursion (TAPSE) and right ventricular ejection fraction (RVEF) in the assessment of global and regional right ventricular function, respectively.
\end{abstract}

Methods: This was a prospective study of 61 cardiac surgical patients. TAPSE was measured with transthoracic echocardiography and RVEF was obtained by a thermodilution pulmonary artery catheter. Both measurements were estimated simultaneously during the early postoperative period. Patients with previously identified severe tricuspid insufficiency were excluded from the study to avoid confounding results.

Results: The etiologies for cardiac surgery were surgical pulmonary thromboendarterectomy in 19 patients, valve replacement in 17 patients, heart transplant in 13 patients, and coronary artery bypass graft in 9 patients. Mean RVEF and TAPSE were $26.2 \% \pm 9.7 \%$ and $11.4 \pm 4 \mathrm{~mm}$, respectively. RVEF and TAPSE showed a significant correlation $(\mathrm{r}=0.73, P<.001)$. Weak reverse relationships between TAPSE or RVEF with afterload hemodynamic parameters, mean pulmonary artery pressure, or pulmonary vascular resistance were elucidated.

Conclusions: TAPSE is a robust measure of right ventricular function that correlates with RVEF assessed by pulmonary artery catheter. A noninvasive method such as echocardiography can guide and support invasive monitoring of right ventricular function in cardiac surgical patients. ( $\mathrm{J}$ Thorac Cardiovasc Surg 2016;152:613-20)

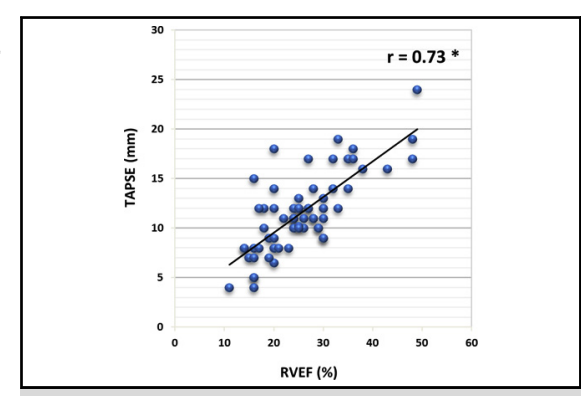

Correlation between tricuspid annular plane systolic excursion and right ventricular ejection fraction after cardiac surgery.

\section{Central Message}

Tricuspid annular plane systolic excursion is a noninvasive measurement of right ventricular function that could guide invasive monitoring in cardiac surgical patients.

\section{Perspective}

Evaluation of right ventricular systolic function is essential to maintaining hemodynamic stability in postoperative cardiac patients; however, assessment of right ventricular function remains difficult. We evaluated the utility of 2 methods: tricuspid annular plane systolic excursion measured by transthoracic echocardiography and right ventricular ejection fraction by thermodilution.

See Editorial Commentary page 620.
Evaluation and monitoring of right ventricular (RV) systolic function is essential to maintaining hemodynamic stability and organ function in a variety of clinical situations,

\footnotetext{
From the antensive Care Medicine Department, Cardiac Intensive Care Unit Division, ${ }^{\mathrm{b}}$ Cardiology Department, and ${ }^{\mathrm{c}}$ Intensive Care Medicine Department, Hospital Universitario 12 de Octubre, Madrid, Spain.

The present study protocol entitled was approved by the Ethics Committee of our institution, with the number $15 / 123$.

Received for publication Aug 20, 2015; revisions received March 5, 2016; accepted for publication April 12, 2016; available ahead of print May 10, 2016.

Address for reprints: Renata Garcia Gigorro, MD, PhD, Intensive Care Medicine Department, Hospital Universitario 12 de Octubre, Avenida de Córdoba, s/n, 28041, Madrid, Spain (E-mail: rennygg@hotmail.com). $0022-5223 / \$ 36.00$

Copyright (c) 2016 by The American Association for Thoracic Surgery http://dx.doi.org/10.1016/j.jtcvs.2016.04.041
}

particularly in the management of critically ill cardiac patients $^{1,2}$; however, although there have been significant improvements in cardiac imaging, the assessment of RV function remains difficult. The most precise methods, such as radionuclide angiography ${ }^{3}$ or magnetic resonance imaging, which is now considered the gold standard for the assessment of right ventricular ejection fraction

Scanning this QR code will take you an imaging video for the article.

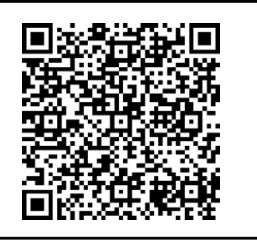




\section{Abbreviations and Acronyms \\ ICU = intensive care unit \\ PAC = pulmonary artery catheter \\ $\mathrm{RV} \quad=$ right ventricular \\ $\mathrm{RVEF}=$ right ventricular ejection fraction \\ TAPSE $=$ tricuspid annular plane systolic excursion \\ $\mathrm{TR}=$ tricuspid regurgitation}

(RVEF), ${ }^{4}$ cannot usually be used in the intensive care unit (ICU).

Echocardiography is a simple technique that is used widely in the ICU; however, standard 2-dimensional echocardiographic evaluation of $\mathrm{RV}$ is time-consuming and likely to result in unreliable data because of the complex geometry of the right ventricle. ${ }^{5}$ Tricuspid annular plane systolic excursion (TAPSE), developed by Kaul et $\mathrm{al}^{3}$ in 1984, is one of echocardiographic surrogates for RV systolic function that has generated greater interest for use in patients with cardiac disease. ${ }^{3,6-8}$ Tricuspid annular motion reflects the contraction and relaxation of the longitudinal myocardial fibers in the right ventricle, and its normal value is greater than $16 \mathrm{~mm}^{9}$

The thermodilution volumetric method is another option for the evaluation of RV function and has been found useful in patients with right heart dysfunction. ${ }^{10}$ This simple technique only requires a pulmonary artery catheter (PAC), which is able to provide direct hemodynamic data and sequential, beat-to-beat determinations of RVEF at the bedside of critically ill patients undergoing cardiac surgery. The normal range of RVEF varies between $40 \%$ and $76 \%$, depending on the methodology used, including the thermodilution technique. ${ }^{11-13}$ Despite being invasive, the rate of associated serious complications for this method is low; thus, the use of this catheter in selected cases of cardiac surgery is still justified because it will significantly contribute to the hemodynamic management. ${ }^{14}$

A comprehensive assessment of RV function is essential after cardiac surgery, especially in patients undergoing a cardiac transplant or in those with significant preoperative pulmonary hypertension. The aim of this study was to determine the correlation between a noninvasive method, such as TAPSE, and an invasive one, such as the RVEF obtained by a PAC, in terms of evaluating RV systolic function in postoperative cardiac surgery patients.

\section{METHODS \\ Patients}

This was a prospective, observational cohort study that was approved by the Ethics Committee of our institution. Seven hundred fifty-three patients who were transferred to the ICU in the postoperative period after cardiac surgery between February 2013 and December 2014 were considered as potential candidates for inclusion in this analysis. Patient inclusion criteria were the following: (1) to be in the early postoperative period, defined as the first 5 days after surgery; (2) to have a PAC placed ( $\mathrm{n}=176$ ); and (3) to have a good-quality echocardiographic imaging of the velocity of the subject's tricuspid annular motion. Forty-five patients with previously identified severe tricuspid insufficiency were excluded from the study. Our Cardiovascular Intensive Care Unit is a closed, 14-bed unit staffed by highly trained intensivists. After admission to the ICU, all patients were treated according to ICU protocols. Echocardiographic and thermodilution catheter measurements were obtained simultaneously and only once from each of the patients during the period of the study.

A total of 61 patients $(8 \%)$ were recruited prospectively to the study. The most frequent etiologies for cardiac surgery were surgical pulmonary thromboendarterectomy in 19 patients with chronic thromboembolic pulmonary hypertension $(31.1 \%)$ and valve replacement in 17 patients $(27.9 \%)$. Off-pump surgery (or without cardiopulmonary bypass) was performed in 4 patients and on-pump surgery in 57 (93.4\%). Of them, 8 patients were administered antegrade cardioplegia, 6 patients received retrograde cardioplegia, whereas 43 patients were administered combined antegrade plus retrograde cardioplegia. Thirty-six patients $(59 \%)$ were receiving mechanical ventilation at the moment of enrollment. Only 2 patients were under pulmonary vasodilator therapy when measurements were obtained.

\section{Right Heart Catheterization}

Right heart catheterization was performed via the internal jugular or the subclavian vein. A 7.5-F quadruple-lumen, balloon-tipped, flow-directed Swan-Ganz catheter (model 774HF7; Edwards Lifesciences, Irvine, Calif) was advanced through the right heart cavities and the pulmonary artery to the pulmonary capillary wedge position. Continuous RVEF measurement was obtained by a pulsed warm thermodilution technique used with the catheter. Detailed, technical aspects of this method have been published previously. ${ }^{15}$

\section{Echocardiographic Study}

All individuals were studied in a supine position with a transthoracic ultrasound device (model ClearVue 350; Philips, Amsterdam, The Netherlands) equipped with a phase-array transducer of 2.5 MHz. TAPSE was obtained in an apical 4-chamber view with the M-mode cursor placed through the lateral tricuspid annulus, at the junction of the tricuspid valve plane with the free wall of the right ventricle (Figure 1). Image acquisition and analysis were performed by a cardiologist and an experienced intensivist (Video 1).

\section{Hemodynamic Measurements}

Heart rate and systolic, diastolic, and mean arterial pressures were measured in all patients. Measurements of mean right atrial pressure, systolic pulmonary artery pressure, diastolic pulmonary artery pressure, mean pulmonary artery pressure, and pulmonary capillary wedge pressure were obtained with a mechanoelectrical transducer with patients in a supine position. Volume parameters like cardiac index, RVEF, RV end-diastolic volume index, and pulmonary vascular resistance index were measured by the beat-to-beat thermodilution method. Finally, mixed venous oxygen saturation also was obtained. Tricuspid annular plane systolic excursion and left ventricular ejection fraction were assessed by echocardiography. Dobutamine, norepinephrine, or dopamine dosages were recorded at the same time as hemodynamic and echocardiographic parameters were estimated.

\section{Statistical Analysis}

Data were analyzed with the Statistical Package for the Social Sciences, version 18.0 (SPSS, Inc, Chicago, Ill). Normality of distribution was tested with the Kolmogorov-Smirnov test. Continuous variables were presented as mean and standard deviation if normally distributed, otherwise as median and interquartile range. Categorical variables were presented as a percentage. The Pearson correlation coefficient was used to calculate the correlation between echocardiographic data and the PAC data. Linear 


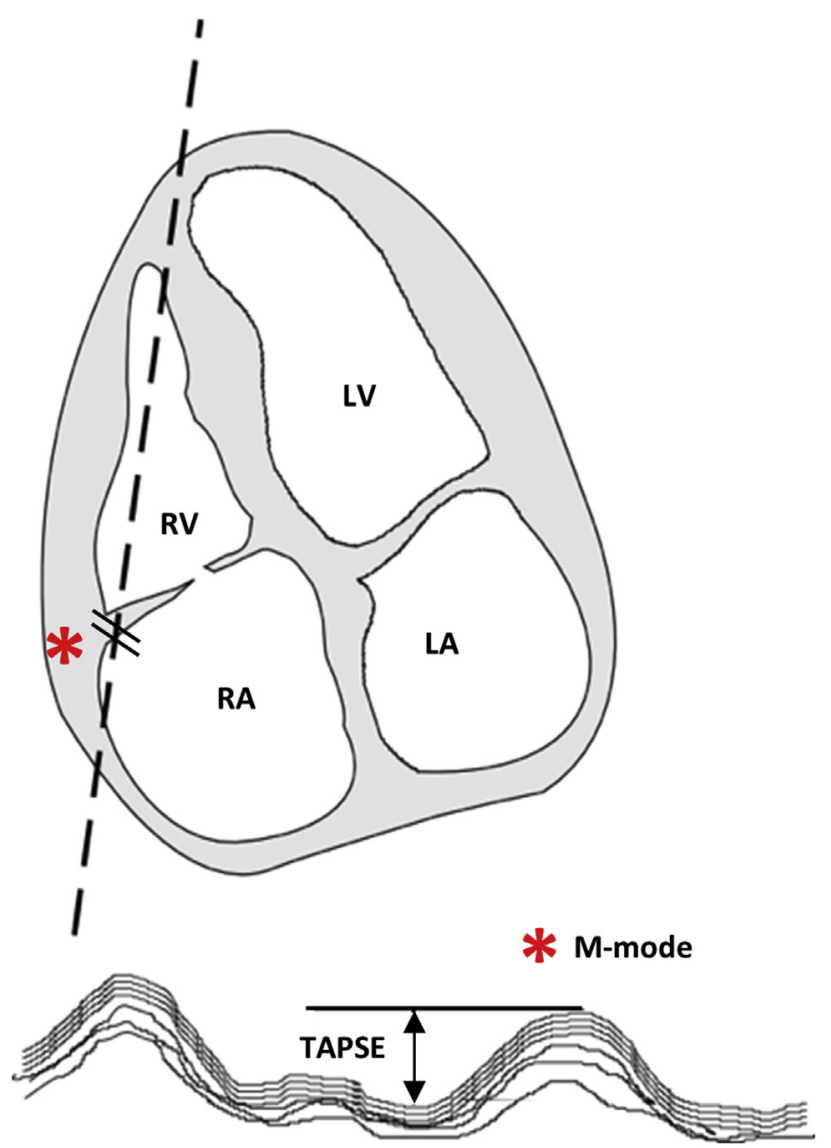

FIGURE 1. Measurement of TAPSE by M-mode cursor (discontinuous line) placed from the lateral annulus of the tricuspid valve $(*)$ in the apical 4-chamber view. $R V$, Right ventricle; $L V$, left ventricle; $R A$, right atrium; $L A$, left atrium; TAPSE, tricuspid annular plane systolic excursion.

regression analysis was performed to assess the correlation between RVEF and TAPSE. The presence of outliers was identified with Cook distance and values above 1.0 were considered influential. A $P$-value of less than .05 was considered statistically significant.

\section{RESULTS}

In the entire cohort $(\mathrm{n}=61)$ patients tended to be male $(59 \%)$, with a mean age of 58.6 years (standard deviation 16.8). The baseline characteristics, echocardiographic, and catheterization data of the population are presented in Table 1.

The mean values of RVEF and TAPSE were $26.2 \% \pm 9.7 \%$ and $11.4 \pm 4 \mathrm{~mm}$, respectively. In addition, preoperative mean values of TAPSE and systolic pulmonary artery pressure, after we excluded cardiac transplant recipients, were $17.3 \pm 4.2 \mathrm{~mm}$ and $63.6 \pm 22.6 \mathrm{~mm} \mathrm{Hg}$, respectively. Table 2 shows the mean values of RV function measurements and cardiac index according to the different cardiac surgical interventions. Interestingly, in the setting of patients undergoing heart transplant, the RVEF and the tricuspid annular plane systolic excursion were lower than the observed in the rest of the patients.
TABLE 1. Patient demographic characteristics and hemodynamic data

\begin{tabular}{|c|c|c|}
\hline & $\mathbf{n}$ & Values \\
\hline Age, y $($ mean $\pm S D)$ & 61 & $58.6 \pm 16.8$ \\
\hline Sex: male $(\%)$ & 36 & $59 \%$ \\
\hline EuroSCORE I (points) (mean \pm SD) & 61 & $6.6 \pm 3.1$ \\
\hline $\begin{array}{l}\text { Cardiopulmonary bypass duration (min) } \\
\quad(\text { mean } \pm \mathrm{SD})\end{array}$ & 61 & $144.1 \pm 65.6$ \\
\hline \multicolumn{3}{|l|}{ Diagnosis $(\%)$} \\
\hline Pulmonary thromboendarterectomy & 19 & $31.1 \%$ \\
\hline Valve replacement & 17 & $27.9 \%$ \\
\hline Orthotopic heart transplant & 13 & $21.3 \%$ \\
\hline Coronary artery bypass graft & 9 & $14.8 \%$ \\
\hline Others & 3 & $4.9 \%$ \\
\hline \multicolumn{3}{|l|}{ Clinical (mean $\pm \mathrm{SD}$ ) } \\
\hline MAP (mm Hg) & 61 & $78.8 \pm 10.1$ \\
\hline HR (bpm) & 61 & $93.1 \pm 11.3$ \\
\hline \multicolumn{3}{|l|}{ Vasoactive drugs (mean $\pm \mathrm{SD}$ ) } \\
\hline Dobutamine $(\mu \mathrm{g} / \mathrm{kg} / \mathrm{min})$ & 39 & $8.2 \pm 5.2$ \\
\hline Dopamine ( $\mu \mathrm{g} / \mathrm{kg} / \mathrm{min})$ & 7 & $6.2 \pm 4.4$ \\
\hline Noradrenaline $(\mu \mathrm{g} / \mathrm{kg} / \mathrm{min})$ & 22 & $0.3 \pm 0.2$ \\
\hline \multicolumn{3}{|l|}{ Hemodynamic values PAC (mean \pm SD) } \\
\hline RVEF (\%) & 61 & $26.2 \pm 9.7$ \\
\hline $\operatorname{RVEDVI}\left(\mathrm{mL} / \mathrm{m}^{2}\right)$ & 61 & $122.1 \pm 39.4$ \\
\hline mRAP (mmHg) & 61 & $12.2 \pm 3.6$ \\
\hline sPAP (mm Hg) & 61 & $44 \pm 11.8$ \\
\hline dPAP (mm Hg) & 61 & $21.7 \pm 6.8$ \\
\hline mPAP $(\mathrm{mm} \mathrm{Hg})$ & 61 & $29.5 \pm 7.9$ \\
\hline Cardiac index $\left(\mathrm{L} / \mathrm{min} / \mathrm{m}^{2}\right)$ & 61 & $2.7 \pm 0.5$ \\
\hline PCWP (mm Hg) & 56 & $13.8 \pm 3$ \\
\hline $\mathrm{SvO}_{2}(\%)$ & 61 & $64.5 \pm 9$ \\
\hline PVRI $\left(\right.$ dyn $\left.\cdot \mathrm{s} / \mathrm{cm}^{5}\right)$ & 56 & $480.9 \pm 236.7$ \\
\hline \multicolumn{3}{|l|}{ Echocardiography values (mean \pm SD) } \\
\hline TAPSE (mm) & 61 & $11.4 \pm 4$ \\
\hline $\operatorname{LVEF}(\%)$ & 61 & $52.9 \pm 10.3$ \\
\hline
\end{tabular}

SD, Standard deviation; EuroSCORE, European System for Cardiac Operative Risk Evaluation; $M A P$, mean arterial pressure; $H R$, heart rate; $P A C$, pulmonary artery catheter; $R V E F$, right ventricular ejection fraction; RVEDVI, right ventricular enddiastolic volume index; $m R A P$, mean right atrial pressure; $s P A P$, systolic pulmonary artery pressure; $\triangle P A P$, diastolic pulmonary artery pressure; $m P A P$, mean pulmonary artery pressure; $P C W P$, pulmonary capillary wedge pressure; $\mathrm{SvO}_{2}$, mixed venous oxygen saturation; PVRI, pulmonary vascular resistance index; TAPSE, tricuspid annular plane systolic excursion; $L V E F$, left ventricular ejection fraction.

A significant close correlation between RVEF and TAPSE was observed $(\mathrm{r}=0.73, P<.001)$ and is represented in Figure 2. Linear regression analysis revealed a significant association between TAPSE and RVEF (beta slope 1.77; $95 \%$ confidence interval, $1.33-2.21 ; \mathrm{y}=5.96+1.77 \mathrm{x}$; $\left.\mathrm{r}^{2}=0.52 ; P<.001\right)$, and influential outliers were not found on the association. In addition, Table 2 and Figure 3 show significant correlations between TAPSE and RVEF after different types of heart surgeries.

TAPSE and RVEF were explored for a possible dependency on preload and afterload conditions of the right chambers. A heterogeneous pattern of correlation is displayed in Figure 4. Weak inverse correlations were noted when we examined the relationship between RVEF or 
TABLE 2. Measures of right ventricular function and cardiac index according to surgical interventions

\begin{tabular}{lcccc}
\hline \multicolumn{1}{c}{ Variables } & $\begin{array}{c}\text { PTE } \\
(\mathbf{n}=\mathbf{1 9})\end{array}$ & $\begin{array}{c}\text { Valve replacement } \\
(\mathbf{n}=\mathbf{1 7})\end{array}$ & $\begin{array}{c}\text { Heart transplant } \\
(\mathbf{n}=\mathbf{1 3})\end{array}$ & $\begin{array}{c}\text { CABG } \\
(\mathbf{n}=\mathbf{9})\end{array}$ \\
\hline TAPSE $(\mathrm{mm})$ & $11.4 \pm 2.6$ & $11.3 \pm 4.2$ & $9.7 \pm 4.4$ \\
RVEF $(\%)$ & $25.8 \pm 5.2$ & $25.2 \pm 9.3$ & $20.7 \pm 7.8$ & $13.5 \pm 4.3$ \\
mPAP $(\mathrm{mm} \mathrm{Hg})$ & $32.2 \pm 6.3$ & $32.2 \pm 9.1$ & $29.1 \pm 6.6$ & $31.4 \pm 8.5$ \\
PVRI $\left(\mathrm{dyn} \cdot \mathrm{s} / \mathrm{cm}^{5}\right)$ & $486.3 \pm 212.3$ & $470.3 \pm 306.7$ & $547.9 \pm 243.4$ & $20.1 \pm 4.1$ \\
Cardiac index $\left(\mathrm{L} / \mathrm{min} / \mathrm{m}^{2}\right)$ & $2.97 \pm 0.6$ & $2.6 \pm 0.5$ & $2.6 \pm 0.4$ & $2.58 \pm 0.5$ \\
Correlation: TAPSE and RVEF & $\mathrm{r}=0.54$ & $\mathrm{r}=0.74$ & $\mathrm{r}=0.73 \quad(P=.004)$ & $(P=0.74$ \\
& $(P=.017)$ & $(P=.001)$ & $(P=001)$ \\
\hline
\end{tabular}

Results are expressed in mean and SD. PTE, Pulmonary thromboendarterectomy; $C A B G$, coronary artery bypass graft; $T A P S E$, tricuspid annular plane systolic excursion; $R V E F$, right ventricular ejection fraction; $m P A P$, mean pulmonary artery pressure; $P V R I$, pulmonary vascular resistance index.

TAPSE and both, pulmonary vascular resistance index, and mean pulmonary artery pressure. In addition, influential outliers were not present in the data. Finally, no significant correlation between RVEF and cardiac index was found $(\mathrm{r}=0.19, P=.121)$.

\section{DISCUSSION}

In the present study, we found that RV systolic function, assessed by the use of either invasive or noninvasive methods, was reduced in a subgroup of patients after cardiac surgery. In addition, we found a close correlation between TAPSE, measured by transthoracic echocardiography, and RVEF, obtained by a thermodilution PAC.

Subsequent to cardiac surgery with cardiopulmonary bypass and pericardial incision, patients show a marked change in the RV contractile pattern, with a relative loss of

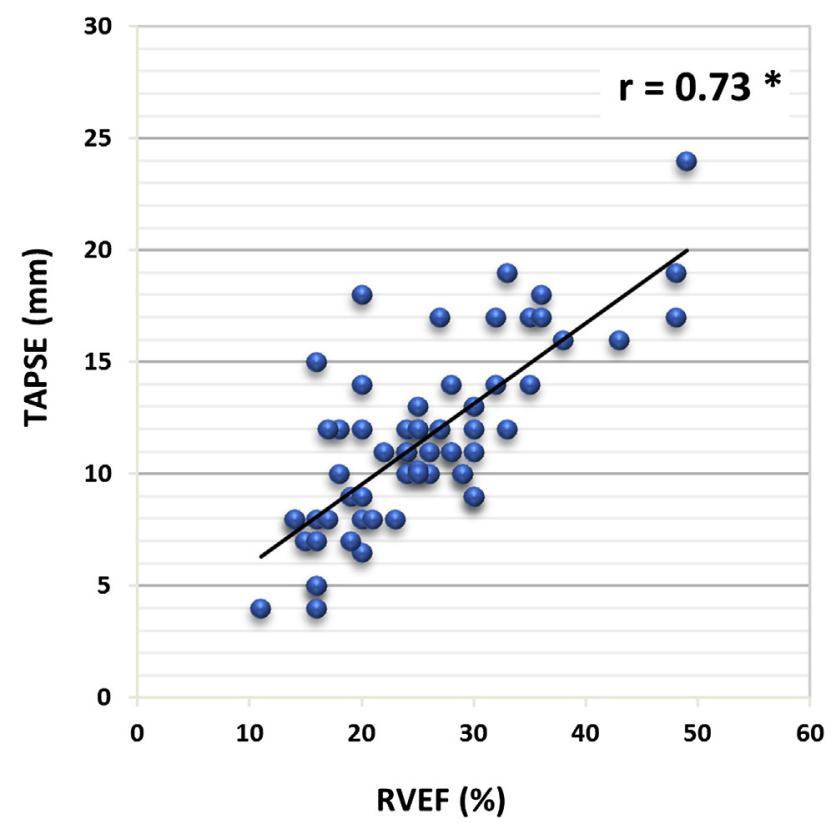

FIGURE 2. Solid line shows a good correlation between TAPSE and RVEF. $* P<.001$. TAPSE, Tricuspid annular plane systolic excursion; $R V E F$, right ventricular ejection fraction. longitudinal shortening and gain in transverse shortening, despite normal global RV function ${ }^{16}$ and left ventricular function, ${ }^{17}$ resulting in a diminished TAPSE values in our population in line with a previous study. ${ }^{18}$ The reasons for these changes have not yet been determined, although a number of mechanisms have been proposed. ${ }^{16,19-22}$ As has been shown, TAPSE was particularly low in patients after heart transplantation. In these patients, RV dysfunction is a common complication, ${ }^{23}$ which occurs as a result of a poor myocardial protection, a prolonged donor ischemic time, and a donor right ventricle not adapted to elevated pulmonary vascular resistance in the recipient, as a consequence of the end stage heart failure.

Our results agree with the findings of other studies that have published a wide variety of good correlations between TAPSE and other surrogates measures of RV function. An important correlation was obtained when TAPSE was compared with RV fractional area, ${ }^{24}$ with peak longitudinal systolic strain, ${ }^{25}$ or with RVEF measured by radionuclide angiography, ${ }^{3,26}$ or by magnetic resonance imaging. ${ }^{4,27-29}$ Regarding the accuracy of RVEF estimated by a modified PAC, it also has been found useful in patients with right heart dysfunction. ${ }^{10,30-32}$ Thereby, good correlations have already been published between RVEF obtained by thermodilution and by biplane angiography ${ }^{10}$ or by nuclear techniques. ${ }^{31}$ When a comparison was made between RVEF by thermodilution and 2-dimensional echocardiographic fractional area change, a good correlation also was demonstrated. ${ }^{30,32}$ As far as we are aware, the present study is the first to evaluate the correlation between TAPSE by M-mode and RVEF by the thermodilution method in a large group of patients after cardiac surgery. Our data show that both parameters are consistent for assessing RV function in cardiac surgical patients.

The influence of different hemodynamic parameters on the assessment of RV systolic function is a well-known phenomenon that has been the subject of previous investigations. ${ }^{33-35}$ The right ventricle is highly sensitive to the imposed pressure load; thus, its systolic function is dependent mainly on its contractility and on afterload that this cardiac chamber must confront. ${ }^{33,35}$ In this study, a 


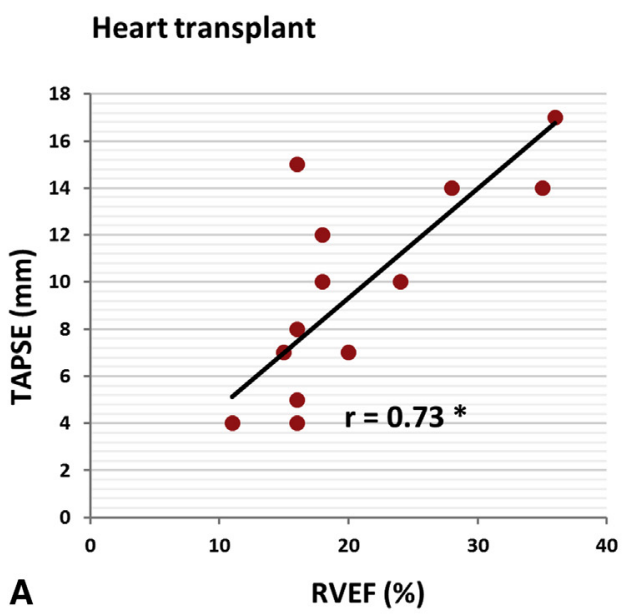

Valve replacement

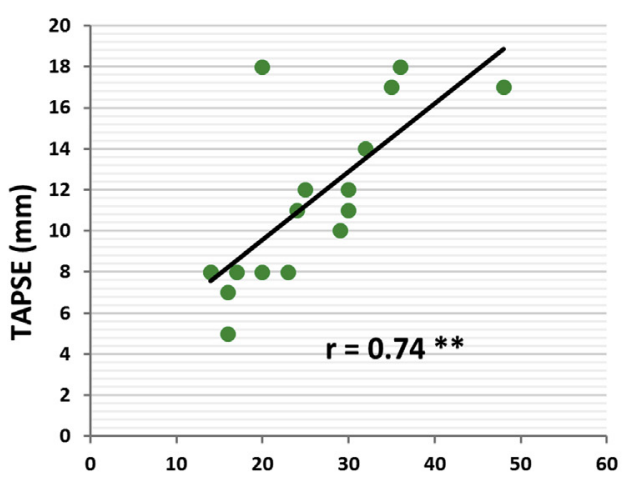

C

RVEF (\%)

\section{Pulmonary thromboendarterectomy}

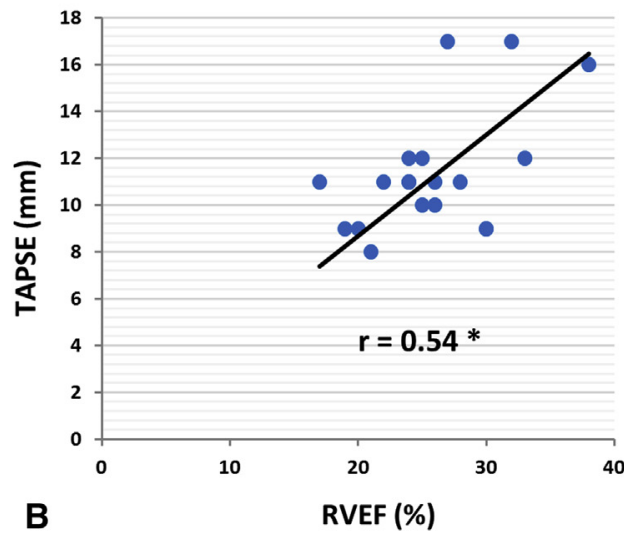

Coronary artery bypass graft

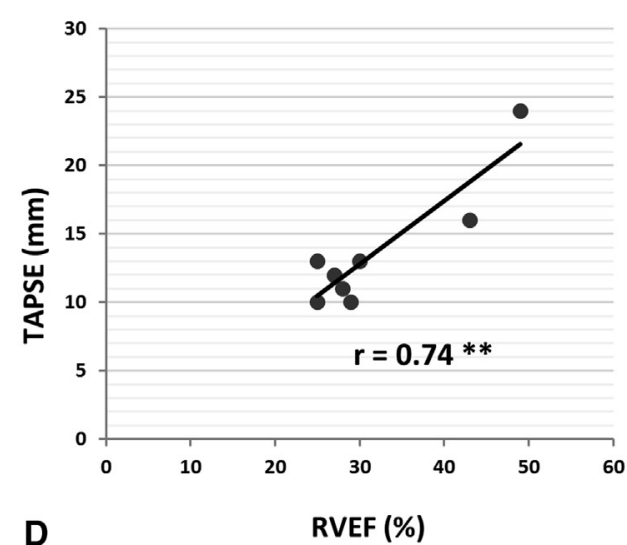

FIGURE 3. Correlations between tricuspid annular plane systolic excursion and right ventricular ejection fraction after different surgical procedures. A, Heart transplant; B, pulmonary thromboendarterectomy; $\mathrm{C}$, valve replacement; and $\mathrm{D}$, coronary artery bypass graft. $* P<.05, * * P=.001$. TAPSE, Tricuspid annular plane systolic excursion; $R V E F$, right ventricular ejection fraction.

weak inverse relationship between TAPSE or RVEF with pulmonary vascular resistance and, to a lesser extent, with mean pulmonary artery pressure were elucidated, in line with previous studies ${ }^{33,35}$; however, a stronger correlation would be desirable. A possible explanation for this finding is that the heterogeneity of cardiovascular disease and its various degrees of RV dysfunction may weaken the linear correlation. In addition, the adaptation of the $\mathrm{RV}$ to changes in afterload is time-dependent after cardiac surgery, and our measurements were obtained only once in the early postoperative period. Likewise, RVEF measured by thermodilution is not related to cardiac index obtained by the same technique, reflecting the absence of dependence between the equations used for the PA catheter software. Thus, RVEF provided by the modified PA catheter is an independent measure for assessing RV function.

Finally, the severe tricuspid regurgitation (TR) is a significantly confounding factor when TAPSE or RVEF are used to evaluate RV function. ${ }^{36}$ A previous study in patients with severe TR showed that a poor correlation between TAPSE and RVEF by the radionuclide method was obtained. ${ }^{36}$ In the same way, PAC measurements underestimated real RVEF in patients with severe TR because of the shape of the thermodilution curve being flattened. In the current study, patients with severe TR were excluded; thus, possible confounding factors were eliminated and the correlation between both parameters is of greater value.

\section{Clinical Implications}

This study suggests that echocardiography in conjunction with the modified PAC are suitable, consistent and, more importantly, complementary methods to monitoring RV function at the bedside in the ICU. In this study, the noninvasive method TAPSE is a valid reference technique for identifying patients with right heart dysfunction, but its major limitation is that a continuous assessment is not possible. Moreover, echocardiographic study may be affected, especially in the immediate postoperative period, by fixed 

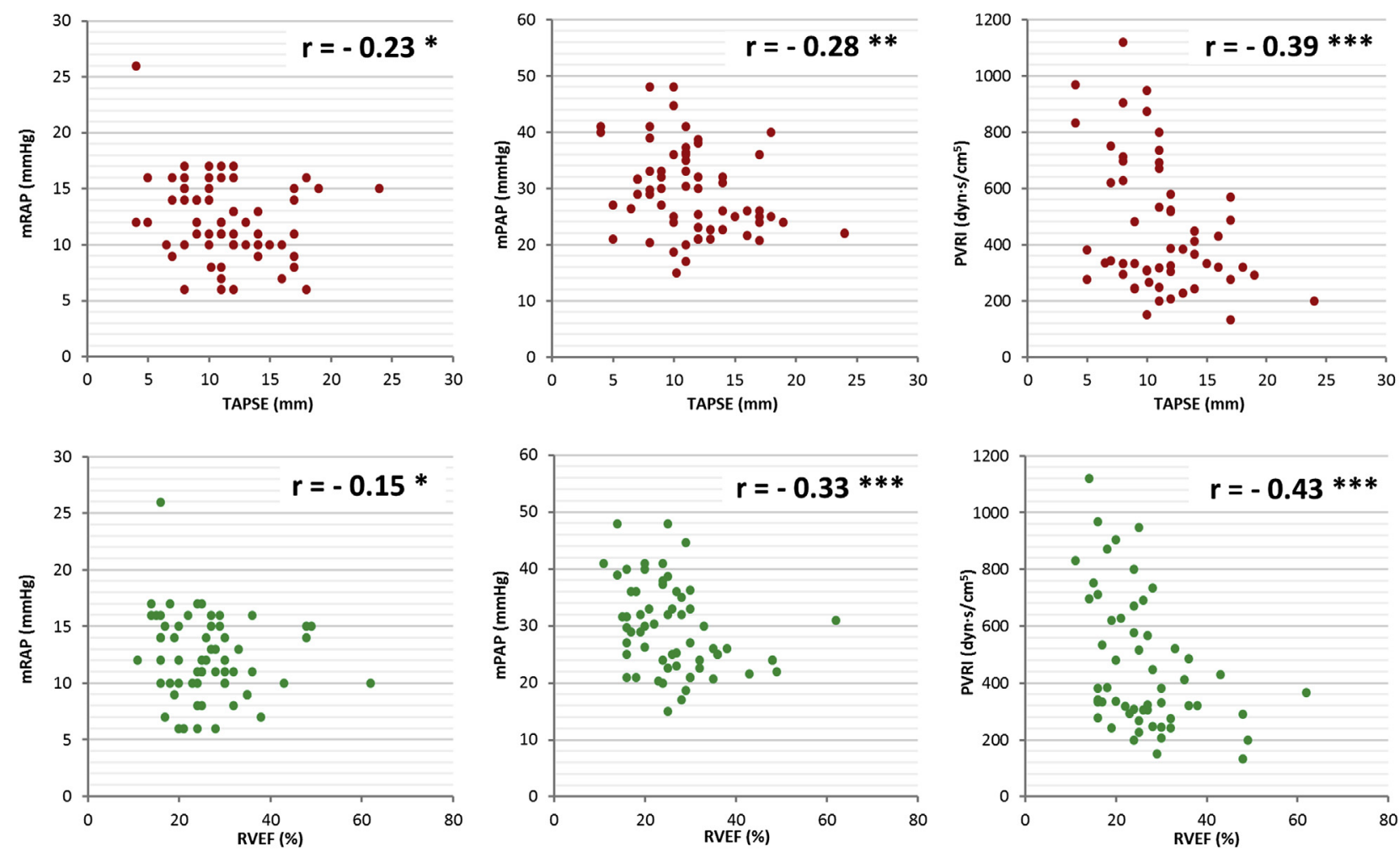

FIGURE 4. Correlations between TAPSE (top) and RVEF (bottom) with preload and afterload parameters. $m R A P$, Mean right atrial pressure; TAPSE, tricuspid annular plane systolic excursion; $m P A P$, mean pulmonary artery pressure; $P V R I$, pulmonary vascular resistance index; $R V E F$, right ventricular ejection fraction. $* P=\mathrm{NS}, * * P<.05, * * * P<.001$.

patient positioning and limited acoustic windows. This subgroup of patients could benefit from a modified PAC to obtain continuous RVEF to guide timely hemodynamic management after cardiac surgery, especially after procedures in which RV failure is relatively common, such as heart transplantation or pulmonary thromboendarterectomy, where intensive hemodynamic treatment is recommended.

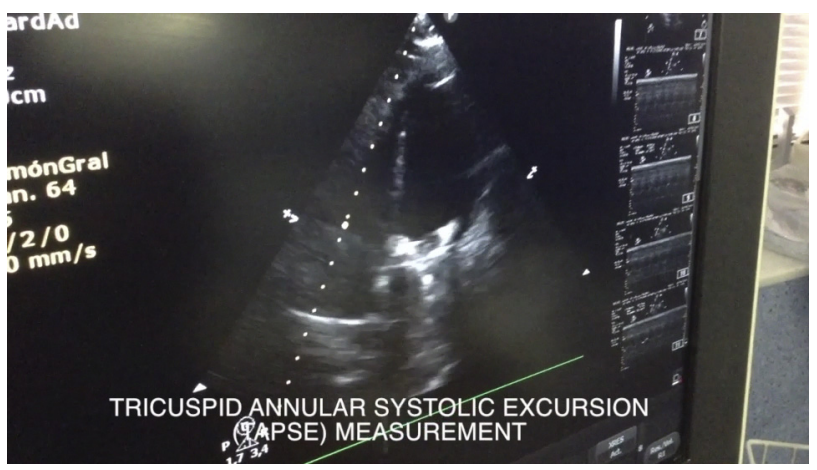

VIDEO 1. Apical 4-chamber view with M-mode cursor placed through the lateral annulus of the tricuspid valve. In this example, the TAPSE obtained was $9.15 \mathrm{~mm}$, and the RVEF measurement in the same patient was $22 \%$. TAPSE, tricuspid annular plane systolic excursion; $R V E F$, right ventricular ejection fraction. Video available at http://www.jtcvsonline. org/article/S0022-5223(16)30131-3/addons.
On the other hand, sequential measurements of TAPSE may play an essential role not only in the diagnosis of RV dysfunction but also in the monitoring of RV function in the following patients: (1) in patients who require invasive monitoring but have contraindications for PAC placement; (2) in patients with no clear indication of PAC monitoring after consideration of the risks and benefits; and (3) in further stages of the clinical course of the same patients, where a noninvasive monitoring approach is desirable.

The present study does have some limitations that warrant mention. This was a single-institution, nonrandomized study. These results are not applicable to individuals with severe TR, because patients with this condition were excluded from the study. A further limitation is that RV function's dependence on heart rate is a variable that was not taken into account. The number of echocardiographic studies realized and the number of patients excluded because of poor acoustic windows were not collected. Thus, the impact of poor acoustic window in patients after cardiac surgery could not be calculated. A total of $27 \%$ of critically ill patients, however, had poor acoustic windows in a previously reported study. ${ }^{37}$ The present study included cardiac surgical patients with different etiologies, which might have significantly affected the results. Finally, the current study was not designed to examine the effects of therapy on TAPSE or RVEF. 


\section{CONCLUSIONS}

This study demonstrates the utility of both tricuspid annular systolic plane excursion and RVEF obtained by thermodilution for the evaluation of RV systolic function in postoperative cardiac patients. TAPSE is a robust, straightforward, and noninvasive measure of RV function obtained from a routine transthoracic echocardiographic examination widely available in the ICU, which could guide and give support to an invasive monitoring of RV function by a PAC.

\section{Conflict of Interest Statement}

Authors have nothing to disclose with regard to commercial support.

\section{References}

1. Itagaki S, Hosseinian L, Varghese R. Right ventricular failure after cardiac surgery: management strategies. Semin Thorac Cardiovasc Surg. 2012;24:188-94.

2. Stobierska-Dzierzek B, Awad H, Michler RE. The evolving management of acute right-sided heart failure in cardiac transplant recipients. J Am Coll Cardiol. 2001;38:923-31.

3. Kaul S, Tei C, Hopkins JM, Shah PM. Assessment of right ventricular function using two-dimensional echocardiography. Am Heart J. 1984;107:526-31.

4. Kjaergaard J, Petersen CL, Kjaer A, Schaadt BK, Oh JK, Hassager C. Evaluation of right ventricular volume and function by $2 \mathrm{D}$ and $3 \mathrm{D}$ echocardiography compared to MRI. Eur J Echocardiogr. 2006;7:430-8.

5. Buckberg G, Hoffman J. Right ventricular architecture responsible for mechanical performance: unifying role of ventricular septum. J Thorac Cardiovasc Surg. 2014;148:3166-71.

6. Haddad F, Couture P, Tousignant C, Denault AY. The right ventricle in cardiac surgery, a perioperative perspective: II. Pathophysiology, clinical importance, and management. Anesth Analg. 2009;108:422-33.

7. Kjaergaard J, Iversen KK, Akkan D, Møller JE, Køber LV, Torp-Pedersen C, et al. Predictors of right ventricular function as measured by tricuspid annular plane systolic excursion in heart failure. Cardiovasc Ultrasound. 2009;7:51.

8. Forfia PR, Fisher MR, Mathai SC, Housten-Harris T, Hemnes AR, Borlaug BA, et al. Tricuspid annular displacement predicts survival in pulmonary hypertension. Am J Respir Crit Care Med. 2006;174:1034-41.

9. Rudski LG, Lai WW, Afilalo J, Hua L, Handschumacher MD, Chandrasekaran K, et al. Guidelines for the echocardiographic assessment of the right heart in adults: a report from the American Society of Echocardiography endorsed by the European Association of Echocardiography, a registered branch of the European Society of Cardiology, and the Canadian Society of Echocardiography. J Am Soc Echocardiogr. 2010;23:685-713.

10. Urban P, Scheidegger D, Gabathuler J, Rutishauser W. Thermodilution determination of right ventricular volume and ejection fraction: a comparison with biplane angiography. Crit Care Med. 1987;15:652-5.

11. Lorenz CH, Walker ES, Morgan VL, Klein SS, Graham TP Jr. Normal human right and left ventricular mass, systolic function, and gender differences by cine magnetic resonance imaging. J Cardiovasc Magn Reson. 1999;1:7-21.

12. Medvedofsky D, Addetia K, Patel AR, Sedlmeier A, Baumann R, Mor-Avi V, et al. Novel approach to three-dimensional echocardiographic quantification of right ventricular volumes and function from focused views. J Am Soc Echocardiogr. 2015;28:1222-31.

13. Lichtwarck-Aschoff M, Leucht S, Kisch HW, Zimmermann G, Blümel G, Pfeiffer UJ. Monitoring of right ventricular function using a conventional slow response thermistor catheter. Intensive Care Med. 1994;20:348-53.

14. Bossert T, Gummert JF, Bittner HB, Barten M, Walther T, Falk V, et al. SwanGanz catheter-induced severe complications in cardiac surgery: right ventricular perforation, knotting, and rupture of a pulmonary artery. J Card Surg. 2006;21: 292-5.

15. Swan HJ, Ganz W, Forrester J, Marcus H, Diamond G, Chonette D. Catheterization of the right heart in man with use of a flow-directed balloon-typed catheter. N Eng J Med. 1970;283:447-51.

16. Raina A, Vaidya A, Gertz ZM, Chambers S, Forfia PR. Marked changes in right ventricular contractile pattern after cardiothoracic surgery: implications for post-surgical assessment of right ventricular function. J Heart Lung Transplant. 2013;32:777-83.

17. Hedman A, Alam M, Zuber E, Nordlander R, Samad BA. Decreased right ven tricular function after coronary artery bypass grafting and its relation to exercise capacity: a tricuspid annular motion-based study. J Am Soc Echocardiogr. 2004; $17: 126-31$.

18. Koestenberger M, Ravekes W, Everett AD, Stueger HP, Heinzl B, Gamillscheg A, et al. Right ventricular function in infants, children and adolescents: reference values of the tricuspid annular plane systolic excursion (TAPSE) in 640 healthy patients and calculation of Z score values. J Am Soc Echocardiogr. 2009;22:715-9.

19. Ahlgren B, Puskas F, Seres T. Total ischemia time alters the longitudinal and circumferential shortening of the right ventricle in transplanted hearts. Semin Cardiothorac Vasc Anesth. 2011;15:163-8.

20. Allen BS, Winkelmann JW, Hanafy H, Hartz RS, Bolling KS, Ham J. Retrograde cardioplegia does not adequately perfuse the right ventricle. J Thorac Cardiovasc Surg. 1995;109:1116-26.

21. Unsworth B, Casula RP, Kyriacou AA, Yadav H, Chukwuemeka A, Cherian A The right ventricular annular velocity reduction caused by coronary artery bypass graft surgery occurs at the moment of pericardial incision. Am Heart J. 2010;159: 314-22.

22. Reynolds HR, Tunick PA, Grossi EA, Dilmanian H, Colvin SB, Kronzon I. Paradoxical septal motion after cardiac surgery: a review of 3,292 cases. Clin Cardiol. 2007;30:621-3.

23. Hosenpud JD, Bennett LE, Keck BM, Boucek MM, Novick RJ The Registry of the International Society for Heart and Lung Transplantation: seventeenth official report-2000. J Heart Lung Transplant. 2000;19: 909-31.

24. Lopez-Candales A, Rajagopalan N, Saxena N, Gulyasy B, Edelman K, Bazaz R. Right ventricular systolic function is not the sole determinant of tricuspid annular motion. Am J Cardiol. 2006;98:973-7.

25. Meris A, Faletra F, Conca C, Klersy C, Regoli F, Klimusina J, et al. Timing and magnitude of regional right ventricular function: a speckle tracking-derived strain study of normal subjects and patients with right ventricular dysfunction. J Am Soc Echocardiogr. 2010;23:823-31.

26. Ueti OM, Camargo EE, Ueti Ade A, de Lima-Filho EC, Nogueira EA. Assessment of right ventricular function with Doppler echocardiographic indices derived from tricuspid annular motion: comparison with radionuclide angiography. Heart. 2002;88:244-8.

27. Ahmad H, Mor-Avi V, Lang RM, Nesser HJ, Weinert L, Tsang W, et al. Assessment of right ventricular function using echocardiographic speckle tracking of the tricuspid annular motion: comparison with cardiac magnetic resonance. Echocardiography. 2012;29:19-24.

28. Speiser U, Hirschberger M, Pilz G, Heer T, Sievers B, Strasser RH, et al Tricuspid annular plane systolic excursion assessed using MRI for semiquantification of right ventricular ejection fraction. Br J Radiol. 2012;85: e716-21.

29. Sato T, Tsujino I, Ohira H, Oyama-Manabe N, Yamada A, Ito YM, et al. Validation study on the accuracy of echocardiographic measurements of right ventricular systolic function in pulmonary hypertension. J Am Soc Echocardiogr. 2012; 25:280-6.

30. Zink W, Nöll J, Rauch H, Bauer H, Desimone R, Martin E, et al Continuous assessment of right ventricular ejection fraction: new pulmonary artery catheter versus transoesophageal echocardiography. Anaesthesia. 2004; 59:1126-32.

31. Dhainaut JF, Brunet F, Monsallier JF, Villemant D, Devaux JY, Konno M, et al Bedside evaluation of right ventricular performance using a rapid computerized thermodilution method. Crit Care Med. 1987;15:148-52.

32. Jardin F, Gueret P, Dubourg O, Farcot JC, Margairaz A, Bourdarias JP, et al. Right ventricular volumes by thermodilution in the adult respiratory distress syndrome A comparative study using two-dimensional echocardiography as a reference method. Chest. 1985;88:34-9.

33. Juillière Y, Buffet P, Marie PY, Berder V, Danchin N, Cherrier F. Comparison of right ventricular systolic function in idiopathic dilated cardiomyopathy and healed anterior wall myocardial infarction associated with atherosclerotic coronary artery disease. Am J Cardiol. 1994;73:588-90.

34. Guazzi M, Bandera F, Pelissero G, Castelvecchio S, Menicanti L, Ghio S, et al. Tricuspid annular plane systolic excursion and pulmonary arterial systolic pressure relationship in heart failure: an index of right ventricular contractile function and prognosis. Am J Physiol Heart Circ Physiol. 2013;305:H1373-81. 
35. Oldershaw P. Assessment of right ventricular function and its role in clinical practice. Br Heart J. 1992;68:12-5.

36. Hsiao SH, Lin SK, Wang WC, Yang SH, Gin PL, Liu CP. Severe tricuspid regurgitation shows significant impact in the relationship among peak systolic tricuspid annular velocity, tricuspid annular plane systolic excursion, and right ventricular ejection fraction. J Am Soc Echocardiogr. 2006;19:902-10.
37. Laver RD, Wiersema UF, Bersten AD. Echocardiographic estimation of mean pulmonary artery pressure in critically ill patients. Crit Ultrasound J. 2014;6:9.

Key Words: right ventricular function, cardiac surgery, TAPSE, RVEF, thermodilution catheter

\title{
EDITORIAL COMMENTARY
}

\section{Finally, Cinderella goes to the party} CrossMark

\author{
Michele Di Mauro, MD
}

\footnotetext{
From the Department of Cardiac Surgery, University "G D'Annunzio" Chieti, Chieti, Italy; and Institute of Cardiovascular Disease, University of L'Aquila, L'Aquila, Italy.

Disclosures: Author has nothing to disclose with regard to commercial support.

Received for publication April 21, 2016; accepted for publication April 26, 2016; available ahead of print May 24, 2016.

Address for reprints: Michele Di Mauro, MD, Staff Surgeon Department of Cardiac Surgery, University “G D’Annunzio” Chieti, Chieti, Italy (E-mail: mdimauro1973@gmail.com).

J Thorac Cardiovasc Surg 2016;152:620-1

0022-5223/\$36.00

Copyright $@ 2016$ by The American Association for Thoracic Surgery

http://dx.doi.org/10.1016/j.jtcvs.2016.04.081
}

The strength of the study in this issue of The Journal by Garcia Gigorro and coworkers ${ }^{1}$ relies on the significant correlation found between tricuspid annular plane systolic excursion (TAPSE) and right ventricular (RV) ejection fraction $(r=0.73)$, as assessed by noninvasive and invasive techniques after cardiac surgery. This finding has 2 major implications from a clinical standpoint. First, it confirms the possibility of monitoring RV function postoperatively with an easily performed noninvasive method (TAPSE). Second, such an echocardiographic measure can guide invasive monitoring of RV function with a pulmonary artery catheter in selected patients only, reducing the rate of possible development of complications. RV dysfunction or dilatation is present in almost half of the patients with hemodynamic compromise after cardiac surgery, ${ }^{2}$ with a mortality of $86 \%$ in the presence of predominately $\mathrm{RV}$ dysfunction, greater than the $30 \%$ to $40 \%$ when left ventricular dysfunction predominates. ${ }^{3}$ As emphasized by Garcia Gigorro and coworkers, ${ }^{1}$ continuous assessment of RV function in the postoperative intensive care unit setting often requires invasive pulmonary hemodynamic monitoring, but this may be avoided in patients with good echocardiographic acoustic windows by means of serial echocardiograms. Another important aspect that emerges from this study is the weak correlation of pulmonary vascular resistance or pulmonary arterial pressure with

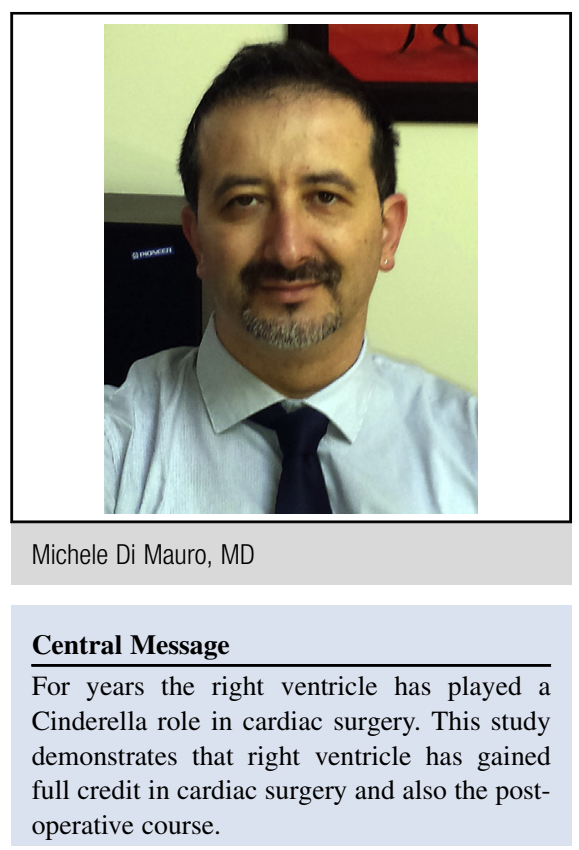

See Article page 613

RV ejection fraction, as assessed by either echocardiography or thermodilution. This provides further evidence that pulmonary hypertension should not be considered as the only prognostic determinant of right heart chamber function.

For years, the RV has played a Cinderella role in both diagnostic workup and prognostic assessment, either before or after cardiac surgery. If we take a glance at the euroSCORE, ${ }^{3}$ pulmonary hypertension is listed among the risk factors, but not RV dysfunction. Yet it is well known that these 2 entities could not coexist in a single patient, who may show RV dysfunction also in the absence of pulmonary hypertension. ${ }^{4}$ Moreover, RV impairment has been shown 